\title{
Factors associated with relapse and remission of alcohol dependent persons after community based treatment
}

\author{
Mary Wangari Kuria \\ Department of Psychiatry, University of Nairobi, Nairobi, Kenya \\ Email: mkuria@uonbi.ac.ke,wangari2@yahoo.com
}

Received 9 December 2012; revised 31 January 2013; accepted 9 February 2013

Copyright (c) 2013 Mary Wangari Kuria. This is an open access article distributed under the Creative Commons Attribution License, which permits unrestricted use, distribution, and reproduction in any medium, provided the original work is properly cited.

\begin{abstract}
Knowledge of factors associated with relapse and remission after treatment for alcohol dependence enables the clinician to offer better individualized treatment. It also enables the clinician to predict which patients are likely to relapse and therefore offer appropriate and effective treatment to prevent relapse. Objective: This study sought to determine the factors associated with remission and relapse in a group of alcohol dependent persons undergoing Community Based Detoxification and Rehabilitation of alcohol dependent persons. Method: One hundred and eighty eight (188) persons with Alcohol Use Disorder Identification Test (AUDIT) positive were subjected to outpatient detoxification for 10 days using a pair of ampoules of high potency Vitamin $B$ and $C$ intravenously daily for 3 consecutive days, diazepam $5 \mathrm{mg}$ and carbamazepine $200 \mathrm{mg}$ for 5 and 10 consecutive nights respectively on an outpatient basis. The participants were visited twice a week (at home) by the community based health workers and reviewed once a week by the principal investigator and attended a bimonthly group therapy session conducted in groups of $20 \mathrm{~s}$ as part of the rehabilitation process. The groups were converted to self-help groups after 4 months to generate income for the participants. Results: Factors significantly associated with relapse to alcohol use included severity of alcohol use and craving for alcohol at intake and the age of onset of alcohol drinking. Further there was a statistically significant predictive value in the mean score of alcohol related problems in the community based group (health, social, financial and legal). Conclusion: Identifying factors that are associated with relapse after alcohol dependence treatment is likely to improve the effectiveness of treatment and prevent relapse in persons at risk.
\end{abstract}

Keywords: Alcohol Dependence; Remission; Relapse; Kenya

\section{INTRODUCTION}

In Africa, many people abstain from alcohol but those that drink, drink a lot [1]. In Kenya, alcohol consumption is the highest in poor communities where potent home brewed alcohol is cheap and readily available. Quality control is weak, and ethanol content can at times be dangerously high [2], examples of such home made brews include, "muratina”, "mnazi”, "changaa”, "mbangari”, "busaa", and "kumikumi". There is spread of heavy use of illicit drug (including illicit alcohol) from urban and historically advantaged groups to rural areas and disadvantaged groups (poor communities) [3]. The recorded per capita consumption of alcohol in Kenya is 1.74 litres of ethanol per capita with an unrecorded consumption of 5 litres per capita [4-8]. Additionally treatment options are few in Kenya and traditionally residential with less than a total of 1000 bed capacity for a population of 40 million. The recorded per capita consumption of alcohol in Kenya is 1.74 litres of ethanol per capita with an unrecorded consumption of 5 litres per capita [4,9].

Despite using different methods, various studies have identified factors associated with remission from alcohol dependence. These factors include: older age at assessment, married, female gender, good social support, younger age at onset of alcohol dependence, less drinking amounts, less severity of drinking [10-14]. Among treated individuals, greater social pressure, more severe alcohol related problems, lack of self efficacy, poor coping skills, co-morbid mood disorder and anxiety disorder have been associated with short-term relapse [1,5-11, 15-23].

Individuals who have experienced more drinking problems and tried previously to reduce their drinking 
without success may be more motivated and ready to learn coping skills imparted in treatment and in Alcoholics Anonymous, raising the likelihood of achieving a good outcome [24].

Remission rates for untreated individuals range between $5 \%$ and $45 \%[7,8]$. Subsequent studies estimate untreated remission rates to range from $50 \%$ to $80 \%$ or more, depending on the severity of alcohol problems. However, these studies focused primarily on general population or media recruited samples; that is, on individuals who had not initiated help seeking and who may have had less severe and as yet unrecognized problems [21,22].

Among treated individuals, short-term remission rates vary between $20 \%$ and $62 \%$, depending on the severity of the disorder and the criteria for remission $[9,10,25]$.

Among both treated and untreated individuals, more frequent and heavier alcohol consumption and more psychological and social drinking problems are associated with a lower likelihood of remission [7,26,27].

Overall, these studies suggest that, especially among individuals who recognize their alcohol problems, treated individuals achieve higher remission rates than untreated individuals do. In treated samples, estimated long-term relapse rates have varied between $20 \%$ and $80 \%[28,29]$.

A range of pharmacological agents have been used in the rehabilitation process. A parenteral high potency drug combination of Vitamin B and C is one of the standard drugs used for alcohol detoxification in hospital settings in Kenya. It is usually given as a pair of ampoules intravenously once daily for 3 - 7 days depending on the level of alcohol dependence. Research evidence supports the use of benzodiazepines as an effective and the preferred choice in the treatment of alcohol withdrawal syndrome especially for the prevention and control of seizures and delirium [30]. In Kenya, Diazepam is commonly used. The use of anticonvulsants as a treatment for acute alcohol withdrawal has been investigated in several studies [31-35], as well as considered in two meta-analyses [36,37] and a review [38], and has been reported to be an effective agent during the period of detoxification.

The objective of the current study was to determine the factors associated with relapse and remission of 188 Alcohol Use Disorder Identification Test (AUDIT) positive participants. This was one of the objectives in a six month prospective study done to determine the cost-effectiveness of community-based and institution-based detoxification and rehabilitation of alcohol dependent persons.

\section{METHODS}

The study was conducted at the Kangemi informal settlement located in the west of Nairobi city in Kenya. The area has a high population and alcohol dependence has been identified as one of the major substances of abuse [39].

\subsection{Participants}

All study participants were aged 18 years and over and therefore legally eligible to consent. Information regarding the study was given before the participants gave consent. Such information included content related to all aspects of detoxification and rehabilitation including medication, dosage and side effects, as well as the right to withdraw at any time during the study. Permission to conduct the study was obtained from the Kenyatta National Hospital/University of Nairobi (KNH/UON) Ethics and Research Committee.

\subsection{Inclusion Criteria}

Consenting participants aged 18 years and over were included in the study if they were alcohol dependent with an AUDIT score of 15 and above for males and 13 and above for females. The cut off AUDIT score for women was set at a lower level than that of the males as recommended [40].

\subsection{Exclusion Criteria}

Excluded from the study were participants with an AUDIT score of $<15$ (for males) and $<13$ (for females) and those unavailable or unwilling to join the study for the 6 months. Also excluded were those suffering from severe medical and neuro psychiatric complications (including delirium tremens, active psychosis as evidenced by hallucinations and delusions, suicidal thoughts and tendencies and severe memory difficulties) at time of screening for intake. Persons found to have a co-morbid psychiatric diagnosis during the process of the study were referred to the outpatient psychiatric clinic where they were attended by a psychiatrist and a psychologist at the study site health center, but continued to be part of the study. Similarly, all participants with medical problems were referred according to the established referral procedure.

A researcher-designed socio-demographic questionnaire (SDQ) was administered at intake to provide necessary information.

A follow up questionnaire designed to obtain the data alcohol use, craving for alcohol, challenges faced by participant and symptoms experienced within the last week.

The Alcohol Smoking Substance Use Identification Screening Test (ASSIST) [41] was used to provide information about the problems related to alcohol dependence. The ASSIST has been found to be a valid screening test for alcohol, cigarette and other substances [42]. In 
addition, the ASSIST is useful in identifying the problems associated with alcohol abuse (health, social, legal and financial). In the current study, the ASSIST was used to identify other substances used by the participants and also the problems related to alcohol use and to determine the extent of alcohol craving. The Composite International Diagnostic Interview (CIDI) instrument was administered to screen for psychiatric co-morbidity. The CIDI allows the investigator to: measure the prevalence of mental disorders, measure the severity of these disorders, determine the burden of these disorders, determine who is treated, remains untreated, and the barriers to treatment [43]. The CIDI was used to screen for the following disorders considered include, anxiety disorders (agoraphobia, generalized anxiety disorder, obsessivecompulsive disorder, panic disorder, posttraumatic stress disorder, social phobia, specific phobia), mood disorders (bipolar I and II disorders, dysthymia, major depressive disorder), disorders that share a feature of problems with impulse control (bulimia and intermitted explosive disorders) and substance disorder (alcohol abuse and dependence, drug abuse and dependence, nicotine). (The principle investigator $[\mathrm{PI}]$ and assistant researcher were trained by DM Ndetei in the use of the CIDI).

The ASSIST and the CIDI were administered both at intake and at six months. Patients found to have an Axis I psychiatric diagnosis were referred and treated at the weekly outpatient psychiatric clinic which operates at the Kangemi health centre. The participants continued with the study while following the psychiatric treatment.

The participants were subjected to alcohol detoxification for 10 days using a pair (each dose includes 2 ampoules that must be mixed when administering) of ampoules of high potency Vitamin B and C intravenously given by intravenous injection daily for 3 consecutive days, oral diazepam $5 \mathrm{mg}$ and carbamazepine $200 \mathrm{mg}$ for 5 and 10 consecutive nights respectively on an outpatient basis from the first day of enrollment in the study. Although the study participants had a general physical examination (including blood pressure, temperature and body weight check), no laboratory or radiological investigations were performed in the current study since the community facility did not have the necessary radiological and laboratory. However all those that required investigations were referred according to the laid down procedures of the Health Centre. Low doses of diazepam and carbamazepine were used for all participants in order to avoid undue sedation as well as might complicate existing medical conditions. Intervention guidelines indicate that oversedation is undesirable in those with hepatic impairment [44].

For a period of 6 months there was documented follow-up at home for each participant by the Community Based Health Worker (CBHW) twice a week, and at the
Kangemi heath center once a week where the participant was seen by the principal investigator (PI) or an assistant. A structured follow up questionnaire was used by both the PI and the CBHW. The follow up questionnaire was researcher designed to obtain the following data; the identity of the individual, history of alcohol use in the last one week and amounts used if any, craving for alcohol, challenges faced by participants within the last week and withdrawal symptoms experienced.

This was completed once a week by the principal investigator and twice a week by the CBHW. Both the PI and the $\mathrm{CBHW}$ reports regarding the drinking status were compiled weekly. Any discrepancy between the two structured reports was addressed during the next home visit by the CBHW.

There was a bimonthly group therapy session conducted in groups of 20 participants by the PI together with a clinical psychologist. After 4 months participants formed a self-help group.

\subsection{Data Analysis and Result Presentation}

Data collected was coded, entered and stored electronically. Only the PI had the name related to the code number. The data was analyzed using STATA version 10 and descriptive and inferential statistics performed. Results are presented in the form of tables for quantitative analysis and narratives for qualitative analysis. A p-value of less than 0.05 was considered to be statistically significant.

\subsection{AUDIT Analysis}

The AUDIT instrument has 10 items related to alcohol behavioral outcomes composed of hazardous drinking, alcohol dependence and alcohol related harm. The items are scored on a scale of 0 to 4 and linearly transformed to 0 to 100 score scale. The sub-scales score are linearized as

$$
S=\frac{(R S)}{\text { Range }} \times 100
$$

where $R S$ is the raw score obtained by taking the sum of the items, and Range is the difference between the maximum possible value of $R S$ and the minimum possible value.

\subsection{ASSIST Analysis}

The alcohol associated problems such as social, health, legal and financial (obtained from the ASSIST instrument) were linearized in the same way to generate an overall alcohol problem score on a scale of 0 to 100 . The final score was compared between pretest and post test at 6 months using a t-test for comparing average scores.

A logistic regression analysis was done to determine 
factors associated with relapse or remission. The dependent variable was binary (whether or not the participants were drinking in the last 3 months before the end of the six month prospective study as determined by the ASSIST questionnaire (question $2 b$ of the ASSIST questionnaire inquires on drinking alcohol use for the last 3 months, and also determines the pattern of use for the same period.

The data obtained by use of the CIDI was analyzed for all anxiety disorders and mood disorders. Data on substance disorders was analyzed from the ASSIST questionnaire.

\section{RESULTS}

A total of 188 participants were enrolled in the study, $92.5 \%$ of whom were male. The participants were young, with a mean age of 31.9. Participants had an early onset of drinking with the majority (92.9\%) of participants having begun alcohol drinking before the age of 25 years. A majority (60.5\%) of the participants began to drink before they attained the recommended drinking age (18 years). The participants had a low monthly income with only $9.1 \%$ of the participants earning more than 429 United State Dollars per month. Majority (51.6\%) of the participants drank alcohol daily. The mean AUDIT score was $\mathbf{2 8 . 6}$ for males and 26.6 for females. Ten participants were reffered to the Kangemi Health centre for treatment of co-morbid disorders.

At the end of six months 130 (69.1\%) out of the 188 enrolled participated in the post test. The CIDI and ASSIST questionnaire was administered. Data analysis showed that seventy four (56.9\%) out of the 130 had not used alcohol for the entire six months as per the follow up reports. This remission rate was consistent with that obtained by the analyses of question 2b of the ASSIST questionnaire filled at the end of six months (the question enquires on alcohol use in the last 3 months). The pattern of alcohol drinking for the group at the beginning of the study was compared with that at six months and there was a statistically significant $(p-v a l u e=0.000)$ reduction in the use of alcohol.

The levels of co-morbidity as determined by the CIDI were high with $63.8 \%$ of them having depression, $45.7 \%$ had specific phobia, $42.6 \%$ had generalized anxiety disorder and $23.9 \%$ had social phobia according to the screening at enrollment. At the end of the six months only $10.7 \%$ had depression, $6.1 \%$ had specific phobia and generalized anxiety disorder. There was a statistically significant reduction in the level of depression to $10.7 \%$, specific phobia and specific phobia to $6.1 \%$ and social phobia to $4.6 \%$.

There were no differences in the socio demographic and other characteristics in the group that remained abstinent and that which relapsed except on three factors namely, alcohol drinking pattern at intake (p-value = 0.046), craving for alcohol at intake $(p$-value $=\mathbf{0 . 0 4 5})$ and the age of onset of alcohol drinking ( $\mathrm{p}$-value = 0.010). As shown in Table 1, those with an AUDIT score of above 20, those drinking on a daily basis, and participants who started using alcohol before the age of 18 were more likely to relapse.

In addition those with high mean score of alcohol related problems were more likely to relapse as shown in Table 2.

\section{DISCUSSION}

Detoxification and rehabilitation of alcohol dependent persons in Kenya is traditionally residential based. Low doses and similar of diazepam and carbamazepine were used in all patients to avoid excessive sedation in patients that were likely to have co-morbid medical disorders.

The majority of the participants had a high AUDIT score. Individuals who had an AUDIT score of over 20 were more likely to relapse to drinking alcohol. Literature indicates that an AUDIT score of over 19 may imply the presence or incipience of alcohol dependence [6]. Such individuals who were drinking daily at intake were more unlikely to stop drinking. Such individuals are likely to be more dependent on alcohol and require more determination to stop drinking. These is consistent with other studies that report a lower likelihood of remission in individuals with frequent and heavy alcohol consumption $[24,45,46]$.

Individuals who had a daily desire for alcohol at intake were found to be unlikely to stop drinking alcohol at the end of six months. The finding is consistent with several relapse theories that utilize the concept of craving as a major etiology in relapse of alcohol dependence [47]. Craving for alcohol is associated with a desire to use the alcohol and those with severe craving are more unlikely to stop drinking alcohol as compared to those with mild craving. This is probably because craving is a sign of biological addiction. It may therefore be important to consider a more intensive and residential form of treatment for alcohol dependent persons with heavy drinking and severe craving.

Individuals who began drinking at or before the age of 18 years were more likely to stop drinking alcohol after six months of treatment was an unexpected finding. Individuals with early onset of alcohol use are likely to have long experience with alcohol related problems including; broken relationships with family and friends, unemployment, lack of income, poverty and general hopelessness. Whether the desperation made them more motivated and determined to stop drinking remains a speculation. Moos et al., 2006, reported that individuals who have experienced more drinking problems and tried previously to reduce their drinking without success may 
Table 1. Odds ratio and p-value for factors associated with remission and relapse.

\begin{tabular}{|c|c|c|c|c|c|c|c|c|c|}
\hline \multicolumn{10}{|c|}{ Drinking status after 6 months } \\
\hline & Not stopped & Stopped & $\%$ & no. & OR & std error & p-value & $95 \%$ & C.I. \\
\hline Male & 41.9 & 58.1 & 91.4 & 170 & & & & & \\
\hline Female & 50.0 & 50.0 & 8.6 & 16 & 0.72 & 0.44 & $0.589^{*}$ & 0.22 & 2.37 \\
\hline Total & & & 100 & 186 & & & & & \\
\hline \multicolumn{10}{|l|}{ Marital status } \\
\hline Single & 43.6 & 56.4 & 40.1 & 73 & & & & & \\
\hline \multirow[t]{2}{*}{ Married } & 41.0 & 59.0 & 51.1 & 93 & 1.11 & 0.54 & $0.773^{*}$ & 0.61 & 2.93 \\
\hline & 60.0 & 40.0 & 8.8 & 16 & 0.52 & 0.27 & $0.345^{*}$ & 0.20 & 1.46 \\
\hline Total & & & 100 & 182 & & & & & \\
\hline \multicolumn{10}{|l|}{ Religion } \\
\hline Protestant & 40.3 & 59.7 & 56.6 & 103 & & & & & \\
\hline Catholic & 50.0 & 50.0 & 36.8 & 67 & 0.67 & 0.26 & $0.307^{*}$ & 0.32 & 1.44 \\
\hline Muslim/Others & 40.0 & 60.0 & 6.6 & 12 & 1.01 & 0.70 & 0.987 & 0.26 & 3.90 \\
\hline Total & & & 100 & 182 & & & & & \\
\hline \multicolumn{10}{|c|}{ Total number of children } \\
\hline No child & 40.7 & 59.3 & 26.5 & 42 & & & & & \\
\hline One & 45.5 & 54.6 & 18.4 & 29 & 0.83 & 0.48 & $0.740^{*}$ & 0.26 & 2.57 \\
\hline Two & 56.3 & 43.8 & 28.5 & 45 & 0.53 & 0.28 & $0.237^{*}$ & 0.19 & 1.51 \\
\hline Three & 13.3 & 86.7 & 15.2 & 24 & 4.47 & 3.82 & $0.080^{*}$ & 0.84 & 23.86 \\
\hline Four and more & 50.0 & 50.0 & 11.4 & 18 & 0.69 & 0.51 & $0.614^{*}$ & 0.16 & 2.95 \\
\hline Total & & & 100 & 158 & & & & & \\
\hline \multicolumn{10}{|c|}{ Severity of drinking (AUDIT score) } \\
\hline Less or $=20$ & 26.7 & 73.3 & 23.6 & 38 & & & & & \\
\hline$>20$ & 48.2 & 51.9 & 76.4 & 123 & 0.39 & 0.18 & $0.046^{* *}$ & 0.16 & 0.98 \\
\hline Total & & & 100 & 161 & & & & & \\
\hline \multicolumn{10}{|c|}{ Craving for alcohol at intake } \\
\hline Not everyday & 23.1 & 76.9 & 24.3 & 36 & & & & & \\
\hline Daily or almost daily & 46.0 & 54.1 & 75.7 & 112 & 0.35 & 0.18 & $0.045^{* *}$ & 0.13 & 0.98 \\
\hline Total & & & 100 & 148 & & & & & \\
\hline \multicolumn{10}{|c|}{ Change in co-morbidities } \\
\hline Decrease & 44.1 & 55.9 & 78.5 & 102 & & & & & \\
\hline No change & 31.3 & 68.8 & 12.3 & 16 & 1.74 & 1.00 & $0.337^{*}$ & 0.56 & 5.36 \\
\hline Increase & 50.0 & 50.0 & 9.2 & 12 & 0.79 & 0.48 & $0.699^{*}$ & 0.24 & 2.61 \\
\hline Total & & & 100 & 130 & & & & & \\
\hline \multicolumn{10}{|c|}{ Age started drinking alcohol } \\
\hline Aged above 18 & 56.0 & 44.0 & 46.7 & 72 & & & & & \\
\hline Aged 18 and under & 31.0 & 69.0 & 53.3 & 82 & 2.83 & 1.14 & $0.010^{* *}$ & 1.29 & 6.22 \\
\hline Total & & & 101 & 154 & & & & & \\
\hline
\end{tabular}

${ }^{*}$ Not statistically significant, ${ }^{* *}$ Statistically significant, C.I.—confidence interval. 
Table 2. Other factors associated with remission and relapse.

\begin{tabular}{lccc}
\hline & Drinking at 6 months & & \\
\hline & Not stopped & Stopped & p-value \\
\hline Average age in years & 31.7 & 31.7 & $0.9928^{*}$ \\
Hazardous drinking (mean score) & 84.2 & 81.0 & $0.3883^{*}$ \\
Alcohol dependence (mean score) & 74.9 & 78.1 & $0.4547^{*}$ \\
Harmful drinking (mean score) & 76.1 & 72.0 & $0.3348^{*}$ \\
Alcohol related problem (mean score) & 16.4 & 23.3 & $0.0450^{* *}$ \\
\hline
\end{tabular}

"Not statistically significant; ${ }^{* *}$ Statistically significant.

be more motivated and ready to learn coping skills imparted in treatment [12]. Many of the participants had tried to stop drinking alcohol (in some cases severally) on their own, but the withdrawal symptoms were a hindrance. (The question on duration of use of alcohol was inconsistently answered because many of the participants had natural remission on and off in the past and the analysis results were omitted).

The current study did not however find any statistically significant association between the sex, age and marital status of the participant and the treatment outcome. This is inconsistent with other studies that show an association between short term remission and female gender, older age and married status [24,45,46,48].

Studies have shown a less favorable outcome of women after treatment, reporting that women have additional treatment needs than men [49-51]. It is possible that there are differences in coping strategies in men and women resulting to different demands in alcohol treatment [44,52]. Additionally, women have been reported to show different patterns of alcohol exposure and different course of the disease [53-55]. The current study had few women as compared to men and sex was not significantly associated with relapse or remission.

Individuals who had a higher mean score of alcohol related problems including, health social, financial and legal problems had a higher likelihood of relapse than those with a lower alcohol related problems mean score. This finding is consistent with findings by other studies $[1,16,17]$. It is likely that persons with more alcohol related problems are likely to resume drinking in an attempt to avoid looking for solutions to their problems or reducing the tension associated with the presence of such problems. This is supported by findings that individuals who lack coping skills and self efficacy are more likely to relapse after alcohol treatment $[7,9]$.

Although the detoxification process was not intense in the current study, the rehabilitation process provided the participant with adequate care to motivate them to remain abstinent. The translation of the study group into a self-help group in the fourth month of the study provided the participants with a social support group, a source of income as well as providing use for their idle time. A study indicates that the beneficial effects of self help groups are attributed in part to the replacement of participants' social network of drinking friends with a fellowship who can provide motivation and support for maintaining abstinence [57]. The current study anticipated relapse related to the multiple alcohol related problems and with the help of Non Governmental Organization (Basic Needs UK in Kenya) assisted the participants to form a self help group. The self help group provided income, opportunities to the recovering participants to form new social relationships and friends and use of idle time.

\section{Limitations of the Study}

A limitation of this study was that the sample was not randomly selected, and those selected were from the same low socio-economic background. Secondly the doses of the benzodiazepine and carbamazepine used for the detoxification process in the alcohol dependent persons were low and this may have contributed to an increase in relapse rate.

\section{CONCLUSION}

Individuals who have heavy alcohol consumption and craving, as well as higher levels of alcohol related problems are more likely to relapse after alcohol treatment. It is, therefore, important to identify indicators of potential relapse after remission before initiating management of alcohol dependence. This would enable the clinician to institute a more intensive therapy and aftercare program to prevent relapse. An aftercare program that provides social support, structuring and utilization of time whilst also addressing financial needs is useful in sustaining abstinence after treatment.

\section{ACKNOWLEDGEMENTS}

University of Nairobi (the research is part of Ph.D. thesis at the Univer- 
sity of Nairobi), Prof. Ndetei and Prof. Obot for supervising the work, Miriam Wanjiru for help in preparing the Manuscript.

\section{REFERENCES}

[1] Jernigan, D.H. and Obot I.S. (2006) Thirsting for the African market. African Journal of Drug and Alcohol Studies, 5, 57-70.

[2] Rocha Silva, L. (2001) The nature and extent of drug use among South Africa young people: A review of research conducted between the mid 1970s and the mid 1990s. CADRE-Centre for Alcohol/Drug Related Research, Pretoria.

[3] World Health Organization (2004) Neuroscience of psychoactive substance use and dependence. Geneva.

[4] World Health Organization (1992) The ICD-10 classification of mental and behavioral disorders: Clinical descriptions and diagnostic guidelines. Geneva.

[5] Babor, T., Higgins Biddle, J., Saunders, J. and Monteiro, M. (2001) AUDIT The Alcohol Use Disorders Identification Test. Guidelines for use in primary care. 2nd Edition, WHO/MSD/MSB/01.6 World Health Organization, Geneva.

[6] Saunders, J.B., Aasland, O.G., Babor T.F., De La Fuente J.R. and Grant, M. (1993) Development of the Alcohol Use Disorders Identification Test (AUDIT): WHO Collaborative project on early detection of persons with harmful alcohol consumption-II. Addiction, 88, 791-804. doi:10.1111/j.1360-0443.1993.tb02093.x

[7] National Institute on Alcohol Abuse and Alcoholism (NIAAA) (2000) Alcohol involvement over the life course. In: Tenth Special Report to the US Congress on Alcohol and Health: Highlights from Current Research. Department of Health and Human Service NIAA.2853, Bethesda. http://pubs.niaa.nih.gov/publications/10report/intro.pdf

[8] Blomqvist, J. (1999) Treated and untreated recovering from alcohol misuse: Environmental influences and perceived reasons for change. Substance Use \& Misuse, 34, 1371-1406. doi:10.3109/10826089909029389

[9] Rehm, J., Room, R., Monterion, M., Gmel, G., Graham, K., Rehn, N., et al. (2004) Global and regional burden of disease attributable to selected major risk factor. WHO, Geneva, 960-1108.

[10] Marlatt, G.A. and Gordon, J.R. (1985) Relapse prevention. Guilford Press, New York.

[11] Rychtarik, R.G., Prue, D.M., Rapp, S.R. and King, A.C. (1992) Self-efficacy, aftercare, and relapse in a treatment program for alcoholics. Journal of Studies on Alcohol and Drugs, 53, 435-440.

[12] Blomqvist, J. (1999) Treated and untreated recovering from alcohol misuse: environmental influences and perceived reasons for change. Substance Use \& Misuse, 34, 1371-1406. doi:10.3109/10826089909029389

[13] Miller, W.R., Walters, S.T. and Bennett, M.E. (2001) How effective is alcoholism treatment in the United States. Journal of Studies on Alcohol and Drugs, 62, 211220.
[14] Monahan, S. and Finney, J. (1996) Explaining abstinence rates following treatment for alcohol abuse. A quantitative synthesis of patient, research design, and treatment effects. Addiction, 91, 787-805. doi:10.1111/j.1360-0443.1996.tb03575.x

[15] Brown, S.A., Vik, P.W., Patterson, T.L., Grant, I. and Schuckit, M.A. (1995) Stress, vulnerability, and alcohol relapse. Journal of Studies on Alcohol and Drugs, 56, 538-545.

[16] Connors, G.J., Maisto, S.A. and Zywiak, W.H. (1996) Understanding relapse in the broader context of posttreatment functioning. Addiction, 91, 173-189. doi:10.1080/09652149638908

[17] Miller, W.R., Westerberg, V.S., Harris, R.J., and Tonigan J.S. (1996) What predicts relapse? Prospective testing of antecedent models. Addiction, 91, 155-171. doi:10.1046/j.1360-0443.91.12s1.7.x

[18] Yates, W.R., Booth, B.M., Reed, D.A., Brown, K. and Masterson, B.J. (1993) Descriptive and predictive validity of a high-risk alcoholism relapse model. Journal of Studies on Alcohol and Drugs, 54, 645-651.

[19] Marlatt, G.A. and Gordon, J.R. (1985). Relapse prevention. Guilford Press, New York.

[20] Rychtarik, R.G., Prue, D.M., Rapp, S.R. and King, A.C. (1992) Self-efficacy, aftercare, and relapse in a treatment program for alcoholics. Journal of Studies on Alcohol and Drugs, 53, 435-440.

[21] Cunningham, J.A. (1999) Resolving alcohol-related problems with and without treatment: the effects of different problem criteria. Journal of Studies on Alcohol and Drugs, 60, 463-466.

[22] Moyer, A. and Finney, J.W. (2002) Outcomes for untreated individuals involved in randomized trials of alcohol treatment. Journal of Substance Abuse Treatment, 23, 247-252. doi:10.1016/S0740-5472(02)00264-7

[23] Kuria, M.W., Ndetei, D.M., Obot, S., Khasakhala, L.I., Bagaka, B.M., Mbugua, M.N. and Kamau, J. (2012) The association between alcohol dependence and depression. International Scholarly Research Network ISRN Psychiatry, 2012, 482802.

[24] Moos, R. and Moos, B. (2006) Rates and predictors of relapse after natural and treated remission from alcohol use disorders. Addiction, 101, 212-222. doi:10.1111/j.1360-0443.2006.01310.x PMid:16445550

[25] Moos, R., Cronkite, R., Finney, J. and Palo Alto, C.A. (1992) Health and daily living form manual. Mind Garden.

[26] McLellan, A.T., Alterman, A.I., Metzger, D.S., Grissom, G.R., Woody, G.E. and Luborsky, L. (1994) Similarity of outcome predictors across opiate, cocaine, and alcohol treatments: Role of treatment services. Journal of Consulting and Clinical Psychology, 62, 1141-1158.

[27] Booth, B.M., Curran, G.M. and Han, X. (2004) Predictors of short-term course of drinking in untreated rural and urban at-risk drinkers: effects of gender, illegal drug use, and psychiatric co-morbidity. Journal of Studies on Alcohol and Drugs, 65, 63-73.

[28] Finney, J., Moos, R. and Timko, C. (1999) The course of 
treated and untreated substance use disorders: Remission and resolution, relapse and mortality. Addictions, 30-49.

[29] Jin, H., Rourke, S.B., Patterson, T.L., Taylor, M.J. and Grant, I. (1998) Predictors of relapse in long-term abstinent alcoholics. Journal of Studies on Alcohol and Drugs, 59, 640-646.

[30] Ebell, M.H. (2006) Benzodiazipine for alcohol withdrawal. American Family Physician, 73, 1191.

[31] Malcolm, R., Myrick, H., Roberts, J., Wang, W., Anton, R.F. and Ballenger, J.C. (2002) The effects of carbamazepine and lorazepam on single versus multiple previous alcohol withdrawals in an outpatient randomized trial. Journal of General Internal Medicine, 17, 349-355. doi:10.1007/s11606-002-0038-1

[32] Reoux, J.P., Saxon, A.J., Malte, C.A. and Sloan, K.L. (2001) Divalproex sodium in alcohol withdrawal: A randomized double-blind placebo-controlled clinical trial. Alcoholism: Clinical and Experimental Research, 25, 1324-1329. doi:10.1111/j.1530-0277.2001.tb02354.x

[33] Rosenthal, R.N., Perkel, C., Singh, P., Anand, O. and Miner, C.R. (1998) A pilot open randomized trial of valproate and phenobarbital in the treatment of acute alcohol withdrawal. American Journal on Addictions, 7, 189-197. doi:10.3109/10550499808998350

[34] Malcolm, R., Roberts, J.S., Wang, W., Myrick, H. and Anton, R.F. (2000) Multiple previous detoxifications are associated with less responsive treatment and heavier drinking during an index outpatient detoxification. Alcohol, 22, 159-164. doi:10.1016/S0741-8329(00)00114-2

[35] Myrick, H., Brady, K.T. and Malcolm, R. (2000) Divalproex in the treatment of alcohol withdrawal. American Journal of Drug Alcohol Abuse, 26, 155-160. doi:10.1081/ADA-100100597

[36] Holbrook, A.M., Crowther, R., Lotter, A., Cheng, C. and King, D. (1999) Meta-analysis of benzodiazepine use in the treatment of acute alcohol withdrawal. CMAJ, 160, 649-655.

[37] Mayo Smith, M.F. (1997) Pharmacological management of alcohol withdrawal: A meta-analysis and evidencebased practice guideline. American Society of Addiction Medicine Working Group on Pharmacological Management of Alcohol Withdrawal. JAMA, 278, 144-151. doi:10.1001/jama.278.2.144

[38] Malcolm, R., Myrick, H., Brady, K.T. and Ballenger, J.C. (2001) Update on anticonvulsants for the treatment of alcohol withdrawal. American Journal on Addictions, 10, 16-23.

[39] Ndetei, D.M. (2007) Baseline study: The mental health situation in kangemi informal settlement Nairobi-Kenya. http://www.basicneeds.org.uk

[40] Reinert, D.F. and Allen, J.P. (2007) The alcohol use disorders identification test: An update of research findings alcoholism. Clinical and Experimental Research, 31, 185-199. doi:10.1111/j.1530-0277.2006.00295.x

[41] Edwards, S.H., Humeniuk, R., Ali, R., Poznyak, V. and Monteiro, M. (2003) The Alcohol, Smoking and Substance Involvement Screening Test (ASSIST): Guidelines for use in primary care (Draft Version 1.1 for Field Test- ing). World Health Organization, Geneva.

[42] Newcombe (2005) Validation of the World Health Organization. Alcohol, Smoking and Substances Involvement Screening Test (ASSIST): Report of the results from the Australian site. Drug and Alcohol Review, 24 217-226. doi:10.1080/09595230500170266

[43] World Health Organization (2004) Neuroscience of psychoactive substance use and dependence. Geneva.

[44] Bouza (2004) Alcohol misuse and withdrawal screening and intervention guideline: Adults, group health cooperative. www.ghc.org/all-sites/guidelines/alcohol

[45] Jarvis, T.J. (1992) Implications of gender for alcohol treatment research a quantitative and qualitative review. British Journal of Addiction, 87, 1249-1261. doi:10.1111/j.1360-0443.1992.tb02734.x

[46] Ornstein, P. and Cherepon, J.A. (1985) Demographic variables as predictors of alcoholism treatment outcome. Journal of Studies on Alcohol and Drugs, 46, 425-432.

[47] Anton, R.F., O’Malley, S.S., Ciraulo, D.A., Cisler, R.A., Couper, D. and Donovan, D.M. (2006). Combine Study Research Group: Combined pharmacotherapies and behavioral interventions for alcohol dependence: The Combine study: A randomized controlled trial. JAMA, 295, 2003-2017. doi:10.1001/jama.295.17.2003

[48] Moser, A.E. and Annis, H.M. (1996) The role of coping in relapse crisis outcome: A prospective study of treated alcoholics. Addiction, 91, 1101-113. doi:10.1046/j.1360-0443.1996.91811013.x

[49] Bottlender, M. and Soyka, M. (2005) Outpatient alcohollism treatment: Predictors of outcome after 3 years. Drug Alcohol Dependence, 80, 83-89. doi:10.1016/j.drugalcdep.2005.03.011

[50] Anton, R.F., O’Malley, S.S., Ciraulo, D.A., Cisler, R.A., Couper, D. and Donovan, D.M. (2006) Combine Study Research Group: Combined pharmacotherapies and behavioral interventions for alcohol dependence: The Combine study: A randomized controlled trial. JAMA, 295, 2003-2017. doi:10.1001/jama.295.17.2003

[51] Grella, C.E., Polinsky, M.L., Hser, Y.L. and Perry, S.M. (1995) Characteristics of women-only and mixed-gender drug abuse treatment programs. Journal of Substance Abuse Treatment, 17, 37-44. doi:10.1016/S0740-5472(98)00045-2

[52] Sigmon, S.T., Stanton, A.L. and Snyder, C.R. (1995) Gender differences in coping: A further result of socialization and role constraint theories. Sex Roles, 33, 565-587. doi:10.1007/BF01547718

[53] McKay, J.R., Lynch, K.G., Pettinatti, H.M. and Shepard, D.S. (2003) An examination of potential sex and race effects in a study of continuing care for alcohol- and cocaine dependent patients. Alcoholism: Clinical and EXperimental Research, 27,1321-1323. doi:10.1097/01.ALC.0000080347.11949.B7

[54] Foster, J.H., Peters, T.J. and Marshall, E.J. (2000) Quality of life measures and outcome in alcohol-dependent men and women. Alcohol, 22, 45-52. doi:10.1016/S0741-8329(00)00102-6

[55] Chou, S.P. and Dawson, D.A. (1994) A study of the gen- 
der differences in morbidity among individuals diagnosed with alcohol abuse and/or dependence. Journal of Substance Abuse, 6, 381-392. doi:10.1016/S0899-3289(94)90306-9

[56] Bischof, G., Rumpf, H.J., Hapke, U., Meyer, C. and John, U. (2001) Factors influencing remission from alcohol dependence without formal help in a representative popu-

\section{APPENDIX}

\section{Definition of Operational Terms}

Harmful drinking is defined as alcohol consumption that results in adverse effects, e.g., physical or psychological harm [1]. High score on questions 7 - 10 of AUDIT indicates that alcohol-related harm is already being experienced [2].

Hazardous drinking is defined as a quantity or pattern of alcohol consumption that places patients at risk for adverse health effects [3]. High score on question 2 or question 3 of the Alcohol Use Disorder Identification Test (AUDIT) indicates consumption at a hazardous level [2].

Alcohol dependence is a cluster of physiological, behavioural and cognitive phenomena in which the use of alcohol takes on a much higher priority for a given individual than other behaviours that once had greater value [1]. High scores on questions 4 - 6, or/and a total AUDIT lation sample. Addiction, 96, 1327-1336. doi:10.1046/j.1360-0443.2001.969132712.x

[57] Humphreys, K., Mankowski, E.S., Moos, R.H. and Finney, J.W. (1999) Do enhanced friendship networks and active coping mediate the effect of self-help groups on substance abuse? Annals of Behavioral Medicine, 21, 54-60.

score of above 19 implies the presence or incipience of alcohol dependence and requires further diagnostic evaluation for alcohol dependence [2].

Heavy drinking is defined as a quantity of alcohol consumption that exceeds an established threshold value. This threshold at more than 14 units per week for men (or $>4$ units per occasion); more than 7 units per week for women (or $>3$ units per occasion); and more than 7 units per week for all adults 65 years and above [4].

Remission: Persons who had not taken alcohol for the past 3 months as detected by the post test Alcohol Smoking Substance Use Identification Screening Test (ASSIST).

Relapse: Persons who had taken alcohol for the past 3 months as detected by the post test ASSIST.

Treated individuals: persons who had undergone the specified detoxification and rehabilitation as described in methods. 